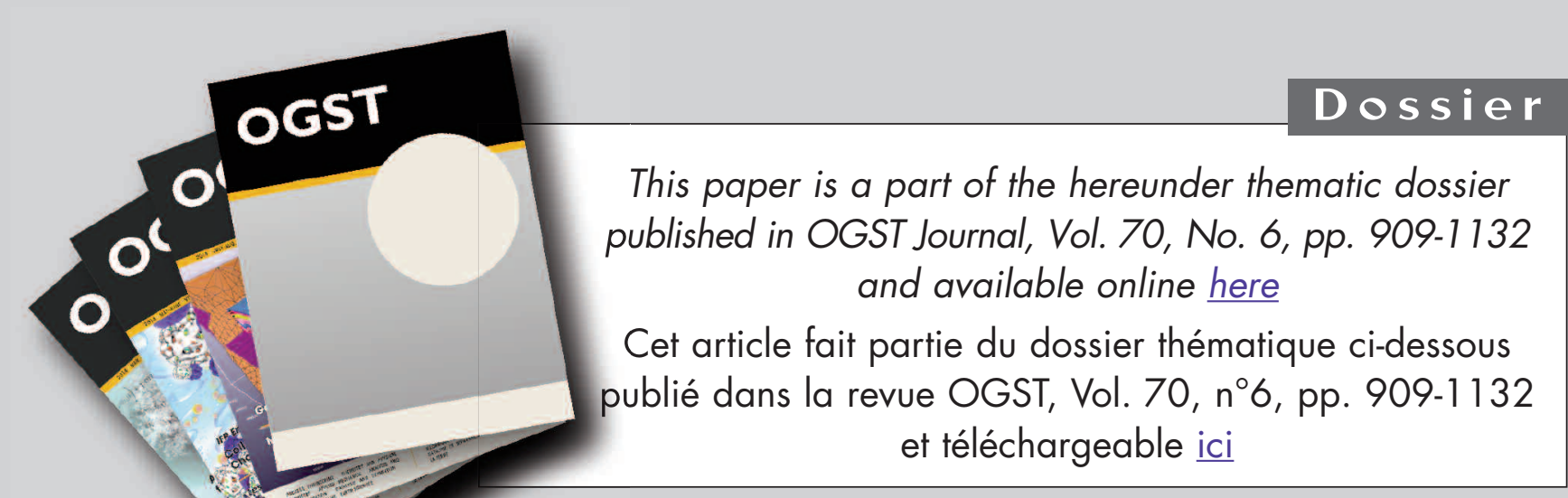

Oil \& Gas Science and Technology - Rev. IFP Energies nouvelles, Vol. 70 (2015), No. 6, pp. 909-1132

Copyright (C) 2015, IFP Energies nouvelles

909 > Editorial - Enhanced Oil Recovery (EOR), Asphaltenes and Hydrates Éditorial - EOR «récupération assistée du pétrole», Asphaltènes et Hydrates D. Langevin and F. Baudin

\section{ENHANCED OIL RECOVERY (EOR)}

917 > HP-HT Drilling Mud Based on Environmently-Friendly Fluorinated Chemicals Boues de forage HP/HT à base de composés fluorés respectueux de I'environnement

I. Henaut, D. Pasquier, S. Rovinetti and B. Espagne

931 > Effective Viscosity in Porous Media and Applicable Limitations for Polymer Flooding of an Associative Polymer

Viscosité effective dans des médias poreux et limites d'application de l'injection de polymères associatifs

P. Zhang, Y. Wang, Y. Yang, W. Chen and S. Bai

$941>$ Dynamic Gelation of HPAM/Cr(III) under Shear in an Agitator and Porous Media Gélification dynamique de HPAM/Cr(III) sous cisaillement dans un agitateur et en milieu poreux

Y. Haiyang, W. Yefei, Z. Jian, L. Peng and S. Shenglong

$951>$ Computer Modeling of the Displacement Behavior of Carbon Dioxide in Undersaturated Oil Reservoirs

Modélisation par ordinateur du comportement de déplacement du dioxyde de carbone dans des réservoirs d'huile non saturés

B. Ju, Y.S. Wu and J. Qin

$967>$ Predicting CO, Minimum Miscibility Pressure (MMP) Using Alternating Conditional Expectation (ACE) Algorithm

Prédiction de la pression miscibilité minimum (MMP) du CO en utilisant un algorithme basé sur l'ACE (Alternating Conditional Expectation)

0 . Alomair, A. Malallah, A. Elsharkawy and M. Iqbal

983 > Towards the Development of Bitumen Carbonates: An Integrated Analysis of Grosmont Steam Pilots

Vers le développement des carbonates bitumineux : une analyse intégrée des pilotes vapeur de Grosmont

C.C. Ezeuko, J. Wang, M.S. Kallos and I.D. Gates

1007> A Novel Model of Foam Flooding Considering Multi-Factors for Enhancing Oil Recovery

Un nouveau modèle d'injection de mousse considérant de multiples facteurs afin d'améliorer la récupération de pétrole

J. Wang, H. Liu, H. Zhang, G. Zhang, P. Liu and K. Sepehrnoori
1025> Testing of Snorre Field Foam Assisted Water Alternating Gas (FAWAG) Performance in New Foam Screening Model

Vérification des performances de la méthode FAWAG (Foam Assisted Water Alternating Gas) sur le champ de Snorre, en Norvège, avec un nouveau modèle de sélection des mousses

P. Spirov and S. Rudyk

\section{ASPHALTENES}

1035> Structural Study of Asphaltenes from Iranian Heavy Crude Oil Étude structurale d'asphaltènes de pétrole brut lourd iranien L. Davarpanah, F. Vahabzadeh and A. Dermanaki

$1051>$ Experimental Study and Mathematical Modeling of Asphaltene Deposition Mechanism in Core Samples

Étude expérimentale et modélisation mathématique du mécanisme de déposition d'asphaltène dans des carottes de forage

T. Jafari Behbahani, C. Ghotbi, V. Taghikhani and A. Shahrabadi

1075> Prediction of the Gas Injection Effect on the Asphaltene Phase Envelope Prévision Prévision de l'effet d'injection de gaz sur l'enveloppe de phase des asphaltènes P. Bahrami, R. Kharrat, S. Mahdavi and H. Firoozinia

\section{HYDRATES}

1087> Methane Hydrate Formation and Dissociation in the Presence of Silica Sand and Bentonite Clay

Formation et dissociation d'hydrates de méthane en présence de sable de silice et d'argile de bentonite

V. Kumar Saw, G. Udayabhanu, A. Mandal and S. Laik

$1101>$ Prediction of Mass Flow Rate in Supersonic Natural Gas Processing Prédiction du débit massique dans les applications de traitement supersonique du gaz naturel

C. Wen, X. Cao, Y. Yang and Y. Feng

$1111>$ Experimental Study on Hydrate Induction Time of Gas-Saturated Water-in-Oil Emulsion using a High-Pressure Flow Loop

Étude expérimentale sur le temps d'induction d'hydrate d'une émulsion eau-enhuile saturée en gaz en utilisant une boucle à circulation sous haute pression X.F. Lv, B.H. Shi, Y. Wang, Y.X. Tang, L.Y. Wang and J. Gong

1125> Hollow Silica: A Novel Material for Methane Storage La silice creuse : un nouveau matériau pour le stockage de méthane V.D. Chari, P.S.R. Prasad and S.R. Murthy 


\title{
Dynamic Gelation of HPAM/Cr(III) under Shear in an Agitator and Porous Media
}

\author{
Yu Haiyang ${ }^{1 *}$, Wang Yefei ${ }^{1}$, Zhang Jian ${ }^{2}$, Lv Peng ${ }^{1}$ and Shi Shenglong ${ }^{1}$ \\ ${ }^{\prime}$ School of Petroleum Engineering, China University of Petroleum (East China), Qingdao 266555 - China \\ ${ }^{2}$ Technology Research Dept., CNOOC Research Center, Beijing 100027 - China \\ e-mail: yuhaiyang_upc@live.cn -wangył@upc.edu.cn - zhangjian@cnooc.com.cn - 412106317@qq.com - 297338429@qq.com \\ * Corresponding author
}

\begin{abstract}
Résumé - Gélification dynamique de HPAM/Cr(III) sous cisaillement dans un agitateur et en milieu poreux - La fermeture des eaux et le contrôle du profil constituent l'une des technologies les plus importantes pour l'amélioration de la récupération du pétrole. Afin d'assurer le succès de cette technologie, la clé est de déterminer précisément le temps de gélification et la résistance du gel au cours de l'écoulement du gel en milieu poreux. Le système HPAM (Hydrolyzed PolyAcrylaMide) et le système redox (bichromate de sodium et sulfite de sodium) sont communément utilisés ; leur temps de gélification statique en ampoules et en milieu poreux ont été déterminés, ainsi que le temps de gélification dynamique dans un agitateur et en milieu poreux. Le taux de cisaillement a été considéré comme l'un des principaux facteurs affectant le temps de gélification. Les résultats ont montré que le temps de gélification statique en milieu poreux était bien plus long que celui en ampoules. Le temps de gélification initial (IGT) en milieu poreux était deux ou trois fois plus élevé que celui en ampoules, alors que le temps de gélification final en milieu poreux était de six fois celui en ampoules. Sous cisaillement dans un agitateur, le procédé de gélification a été divisé en quatre phases : induction, augmentation brusque, stabilité et diminution. Avec l'augmentation du taux de cisaillement, le temps de gélification a été prolongé et la résistance du gel a diminué. Un taux de cisaillement critique de la gélification a été observé, au-dessus duquel aucun gel ne se formait. Le cisaillement n'avait quasiment aucune influence sur la résistance du gel au cours du stade d'induction, mais dans le procédé d'augmentation brusque, le cisaillement pouvait rapidement dégrader la résistance du gel. Le temps de gélification dynamique en milieu poreux était bien plus long que celui de la gélification statique en milieu poreux et en ampoules. Lorsque les concentrations de HPAM et de RS (Redox System) étaient augmentées, l'IGT de la gélification dynamique en milieu poreux était réduit.
\end{abstract}

\begin{abstract}
Dynamic Gelation of HPAM/Cr(III) under Shear in an Agitator and Porous Media Water shutoff and profile control is one of the most important technologies to enhance oil recovery. To ensure the success of this technology, the key is to accurately determine gelation time and gel strength during gel flow in porous media. The HPAM (Hydrolyzed PolyAcrylaMide) system and redox system (sodium bichromate and sodium sulfite) is widely used, whose static gelation time in ampoule bottles and porous media was determined, as well as the dynamic gelation time in an agitator and porous media. The shear rate was considered one of the major factors affecting gelation time. The results showed that the static gelation time in porous media was much longer than that in ampoule bottles.
\end{abstract}




\begin{abstract}
The Initial Gelation Time (IGT) in porous media was two or three times that in ampoule bottles, while the final gelation time in porous media was six times that in ampoule bottles. Under shearing in an agitator, the gelation process was divided into four phases: induction, sudden increase, stability and decrease. With the increase in shear rate, gelation time was prolonged and gel strength decreased. There was a critical gelation shear rate, above which there was no gel formed. Shear had almost no influence on gel strength during the induction stage but in the process of sudden increase, shear could degrade gel strength sharply. The time of dynamic gelation in porous media was much longer than that of static gelation in porous media and ampoule bottles. When HPAM and RS (Redox System) concentrations increased, the IGT of dynamic gelation in porous media was shortened.
\end{abstract}

\section{INTRODUCTION}

With the development of oilfields, the strips of high permeability emerge in the process of water flooding; and it is very important to enhance the volumetric sweep efficiency after water flooding. The most direct and effective way is profile control and water shutoff using crosslinked polymer gel. A gel with a certain gelation time and gel strength can effectively block the strips of high permeability, cause fluid diversion and enlarge sweep efficiency. It is crucial how to determine the gelation time and gel strength during gelant flow.

There are many methods to obtain the static gelation time, such as the code of gel strength [1], the change in viscosity with time [2], the measurement of the storage modulus and loss modulus, application of electrical conductivity and so on. These methods have advantages in themselves. According to Sydansk's gel-strength code, the gel strength is divided into several levels to determine gelation time quickly and effectively. Mokhtari et al. [3] divided gelation time into Initial Gelation Time (IGT) and Final Gelation Time (FGT) with the method of measuring apparent viscosity versus time, and the history of viscosity change during the process of gelation could be recorded. Gao et al. [4] measured the storage modulus and loss modulus and obtained the gelation time by the Winter-Chambon criterion [5]. Basta et al. [6] determined gelation time by the relationship between conductivity and time. Boey et al. [7] obtained the gel point where the tangent phase was found to be independent of the frequency.

Before it is injected into formation, gelant has a variety of shear rates. It is very meaningful to study the effect of shear on the gelant. There has been some research on the effect of shear on gelation time, application performances and re-formation after shear [8-12]. This was conducted under the condition of static gelation. Chauveteau et al. [13] studied the gelation process of polymer and $\mathrm{Cr}$ (III) under stable shear, and the results indicated that it was quite different between gelation under shear and static gelation. Bhaskar et al. [14] studied the effects of different shear rates on the gelation process of a redox system (sulfourea and sodium sulfite), and with the increase in shear rate, the reaction speed was slowed and the gel strength decreased. The results of Kolnes et al. [15] indicated that the viscosity of a gel system could be restored after slowly stable shearing for a long time. The impact of shear on gelation is achieved in at least two ways: one is that shear accelerates the reaction rate by increasing the mobility of polymer and crosslinker molecules. The other is that shear destroys the structure of gel and degrades the strength.

It is very important to study the process of gel flow in porous media. McCool et al. [16] studied the gelation of chromium acetate and polymer during flow in porous media by simulating formation fracture with a long conduit. Gel could be formed in porous media and gelation time was obtained by measuring the resistance coefficient. The results of Seright [17] indicated that a resistance coefficient could be generated by gel in the flow process and firstly increased and then decreased and be stable along the flow direction. The research of Dolan et al. [18] confirmed that the gelation time in porous media was much longer than that in static conditions.

In this paper, with the HPAM (Hydrolyzed Poly Acrylamide) system and redox system, we discuss the static gelation time in ampoule bottles and porous media, and the dynamic gelation time in an agitator and porous media. Furthermore, the relationship between the static gelation time and dynamic gelation time was established, and the critical gelation shear rate was determined with the agitator.

\section{EXPERIMENTAL SECTIONS}

\subsection{Materials}

The polymer employed in this research was classical partially hydrolyzed polyacrylamide (HPAM), whose molecular weight is $1.2 \times 10^{7}$ and the degree of hydrolysis is $22 \%$. The crosslinker was a Redox System (RS), including sodium bichromate and sodium sulfite, and the mass ratio was 1:2. The Synthetic Water (SW) used 
in this study contained $6921 \mathrm{ppm} \mathrm{Na}^{+}, 412 \mathrm{ppm}$ $\mathrm{Ca}^{2+}, 148 \mathrm{ppm} \mathrm{Mg}^{2+}$ and $11853 \mathrm{ppm} \mathrm{Cl}^{-}$.

The experiments of core flooding were operated with sand packs with $2.50 \mathrm{~cm}$ Inner Diameter (ID) and $10.00 \mathrm{~cm}$ length or $100.00 \mathrm{~cm}$ length; the sand packs were filled with clean micro-glass beads of different meshes and saturated by SW. All of the gelation experiments were performed at $75^{\circ} \mathrm{C}$.

\subsection{Static Gelation in Ampoule Bottles}

HPAM solutions of different concentrations were prepared with SW as gelant, and then the crosslinkers (RS) of different concentrations were added. $15 \mathrm{~mL}$ gelant was placed into an ampoule bottle made of thermo-resistant glass. The bottle has a screw cap, and it is $10 \mathrm{~cm}$ long with an ID of $2 \mathrm{~cm}$. The air in the headspace above the solution in the ampoule was replaced with nitrogen to remove any oxygen that could cause gel degradation. A series of samples of each formula were prepared for the following static gelation experiments.

\subsection{Static Gelation in Porous Media}

A series of sand packs with $2.50 \mathrm{~cm}$ ID and $10.00 \mathrm{~cm}$ length were prepared. After being saturated by SW, Pore Volumes (PV) and permeabilities (K) were calculated, then the sand pack was injected into one PV gelants $(\mathrm{HPAM}+\mathrm{RS})$ at the injection speed of $1 \mathrm{~mL} / \mathrm{min}$. Then, the sand packs were sealed and placed in a $75^{\circ} \mathrm{C}$ oven. At regular intervals the breakthrough pressure gradient of each sand pack was measured by SW flooding at the speed of $1 \mathrm{~mL} / \mathrm{min}$.

\subsection{Dynamic Gelation under Shear in an Agitator}

$70 \mathrm{~mL}$ gelant was placed in an agitator and stirred at a certain rotation speed at $75^{\circ} \mathrm{C}$. The viscosity of the gelant was measured by a Brookfield DV-II viscometer at $75^{\circ} \mathrm{C}$ at regular intervals. At the same time, the effect of the shear rate on dynamic gelation was considered by changing the Revolutions Per Minute (RPM). After being stirred for different times, the gelant remained standing in a $75^{\circ} \mathrm{C}$ oven and the viscosity was measured.

\subsection{Dynamic Gelation in Porous Media}

Gelant in the normal conditions was continuously injected into the sand pack of $2.50 \mathrm{~cm}$ ID and $100.00 \mathrm{~cm}$ length, which was saturated by SW and placed in a $75^{\circ} \mathrm{C}$ oven. During the whole process, the change in injection pressure with time was recorded. At the same time, the influencing factors were considered, such as polymer and crosslinker concentrations.

\section{RESULTS AND DISCUSSION}

\subsection{Static Gelation in Ampoule Bottles}

Gelation time is one of the most important parameters. In this paper, the gelation time, which is divided into Initial Gelation Time (IGT) and Final Gelation Time (FGT), was determined by measuring viscosity [3]. IGT is the time of sudden increase in viscosity. FGT is the time when the reaction is nearly finished. The gelation times of different formulas were determined and are shown in Figure 1. The results showed that the process of gelation could be divided into three phases: slow induction, sudden increase and stability. With the increase in concentrations of HPAM and RS, both IGT and FGT decreased. The value of the slope of the sudden increase phase represented the reaction rate. Increase in the concentration of the system could accelerate the reaction rate and shorten IGT, as well as FGT.

\subsection{Static Gelation in Porous Media}

After gelant was injected into porous media, the increase in the following water flooding pressure mainly resulted from plugging by crosslinked gelant and the pressure increased with the degree of crosslinking. When the pressure was finally constant, the crosslinking reaction was completed. The IGT is the time when the water flooding pressure suddenly increases, and the FGT is the first moment when the pressure remains unchanged. The IGT and FGT of static gelation in porous media were obtained by measuring the change in pressure with time; the results are shown in Figure 2. In order to eliminate the effect of permeability on water flooding pressure, vadose force $(F$, unit $\mathrm{N})$ was introduced, which is defined as the required force for fluid flowing through the special core. Numerically, $F$ was equal to the product of water flooding pressure and permeability. From Figure 2, the IGT and FGT of static gelation in porous media were obtained. Furthermore, with increasing concentration of the system, the IGT and FGT decreased. The change in polymer concentration mainly influenced the strength of the gel in porous media; meanwhile, the change in crosslinker concentration mainly influenced gelation time in porous media. The explanation is that the crosslinker RS is an inorganic ion, whose main role is crosslinking polymer molecules and shortening gelation time. However, polymer molecules could enhance the dimensional network structure of gel. 

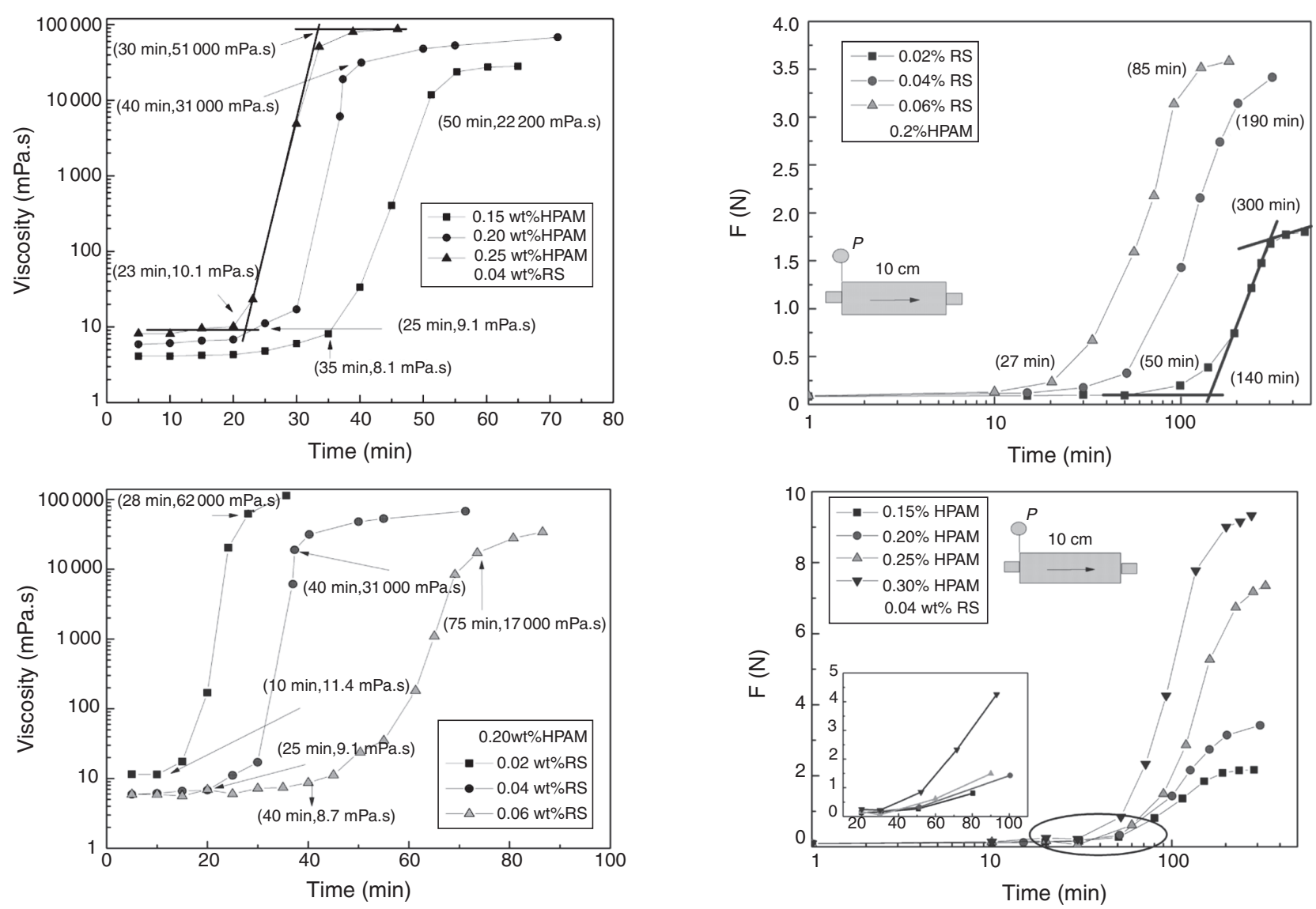

Figure 1

The static gelation in ampoule bottles of system HPAM/ $\mathrm{Cr}(\mathrm{III})$ at $75^{\circ} \mathrm{C}$.

Figure 2

The change of vadose force with time in the process of static gelation o system HPAM $/ \mathrm{Cr}$ (III) in porous media with $2.50 \mathrm{~cm} \mathrm{ID}$ and $10.00 \mathrm{~cm}$ length at $75^{\circ} \mathrm{C}$.

Comparing static gelation in ampoule bottles with static gelation in porous media, it was indicated that both IGT and FGT in porous media were much longer than those in ampoule bottles. Also, IGT in porous media were about three times the IGT in ampoule bottles, while FGT in porous media were about six times the FGT in ampoule bottles. This might result from gelant adsorption and retention in porous media.

\subsection{Dynamic Gelation under Shear in an Agitator}

In the process of water shutoff and profile control, before it is injected into formation, the gelant has a series of shear rates, which influence the gelation time and gel strength. It is very important to analyze the effect of shear on gelation time and gel strength. The classical shear of the agitator was studied with the HPAM system and RS in the following experiments.

\subsubsection{The Effect of the Shear Rate on Gelation Time}

The rotation speed of the agitator, with four paddles ( $2.5 \mathrm{~cm}$ length, $0.8 \mathrm{~cm}$ width and $0.1 \mathrm{~cm}$ thickness; the angle between the paddle and horizontal plane is $45^{\circ}$ ) was in the range of $45 \sim 600 \mathrm{rpm}$. The shear rate was calculated with the method of Metzner and Otto [19]. The vessel for gelant was a cylinder with ID $5.86 \mathrm{~cm}$ and height $2.6 \mathrm{~cm}$. The volume of gelant was $70 \mathrm{~mL}$ in every agitation. The results of the effect of shear on gelation time are displayed in Figure 3. Under different shear rates, the gelation time and gel strength were different. When the shear rate was less than $15.17 \mathrm{~s}^{-1}$, IGT increased with increasing shear rate but was shorter than that in static conditions, and with the increase in shear rate, ultimate gel strength decreased sharply. When the shear rate was up to $18.96 \mathrm{~s}^{-1}$, the system was crosslinked slightly, and the IGT was longer than that in static conditions. Furthermore, FGT in static conditions was 
faster than that at any shear rate. So, it was considered that when the shear rate was higher than $18.96 \mathrm{~s}^{-1}$, no gel existed. A tiny shear could accelerate the reaction between polymer molecules and the crosslinker and was good for the formation of macromolecular aggregates in the stage of induction [6], while the structure of macromolecular aggregates was destroyed by severe shear and IGT was prolonged. The process of gelation under a shear rate (less than $15.17 \mathrm{~s}^{-1}$ ) was divided into four phases: induction, sudden increase, stability and decrease [13].

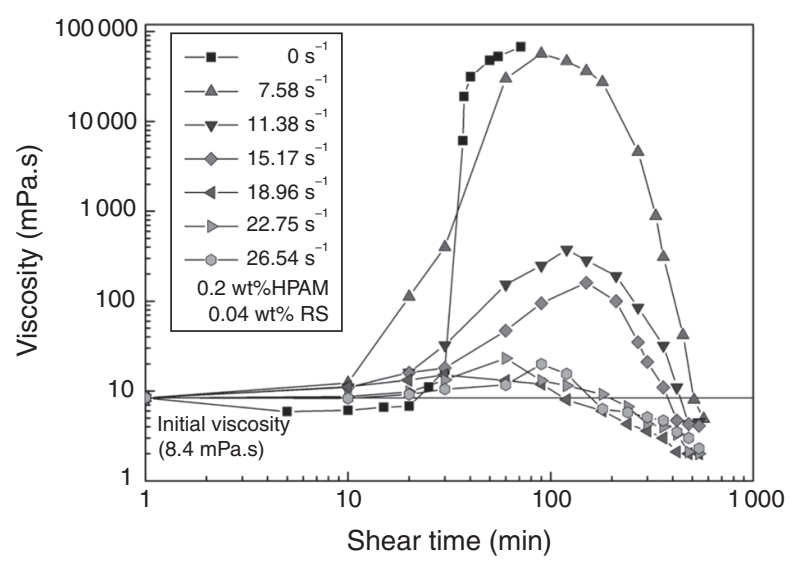

Figure 3

The change of viscosity with shear time under different shear rates with the system of $\mathrm{HPAM} / \mathrm{Cr}(\mathrm{III})$ at $75^{\circ} \mathrm{C}$.

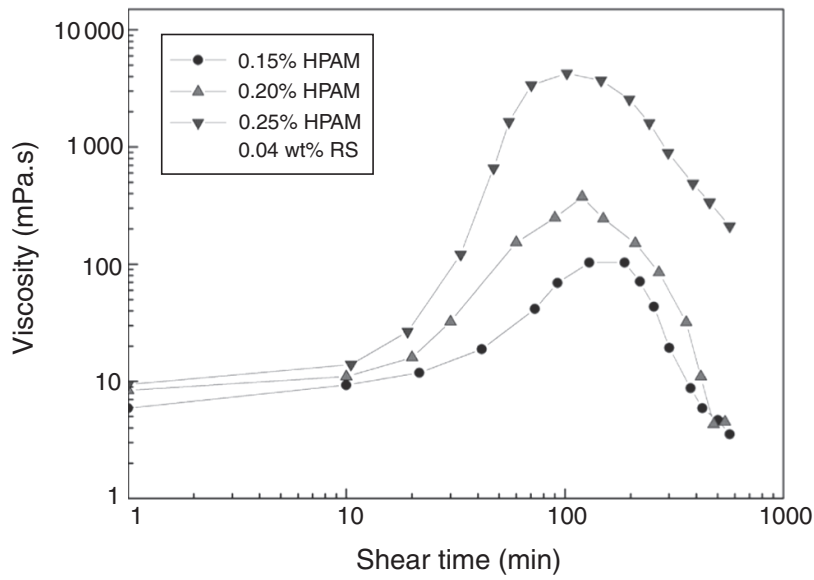

The results of the effect of the concentrations of the polymer and crosslinker on gelation time are shown in Figure 4. When the concentrations of polymer and crosslinker increased, the amount of polymer molecules, crosslinker ions and the probability of a crosslinking reaction increased. This factor resulted in shortened gelation time and increased ultimate gel strength, even under shear conditions.

\subsubsection{Static Gelation after Shearing}

The dynamic gelation process under shear was divided into induction, sudden increase, stability and decrease stages, shown in Figure 5. Viscosity change in the gelant at different gelation stages after shearing for a certain time was a very important factor to study. For this, the experiment was designed as follows: gelant of $0.2 \mathrm{wt} \%$ HPAM and $0.04 \mathrm{wt} \%$ RS was sheared at the rate of $11.38 \mathrm{~s}^{-1}$ at $75^{\circ} \mathrm{C}$ and the shear time lasted for $1 \mathrm{~min}$. Then, the shearing was stopped and the gelant was kept gelling under static conditions. The viscosity of static gelation after shearing for 1 min was measured. The shear time was increased and the experiment was repeated. The relationship between the viscosity of static gelation after different shearing times and shear time was established; the data are shown in Figure 5. For the viscosities of dynamic gelation under shear and static gelation after shearing for different times, shear had almost no effect on gel strength at the stage of induction, but it had an enormous influence on gel strength at the stage of sudden increase. At the stage of sudden increase, the viscosity of dynamic gelation under shear increased

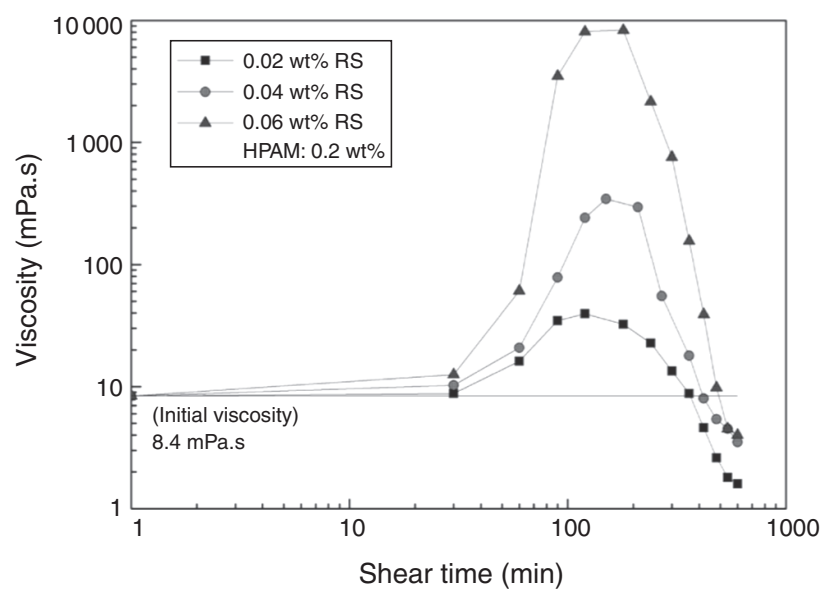

Figure 4

The effect of concentration of polymer and crosslinker on gelation time with the system of HPAM/Cr(III) under shear rate $11.38 \mathrm{~s}^{-1}$ at $75^{\circ} \mathrm{C}$. 


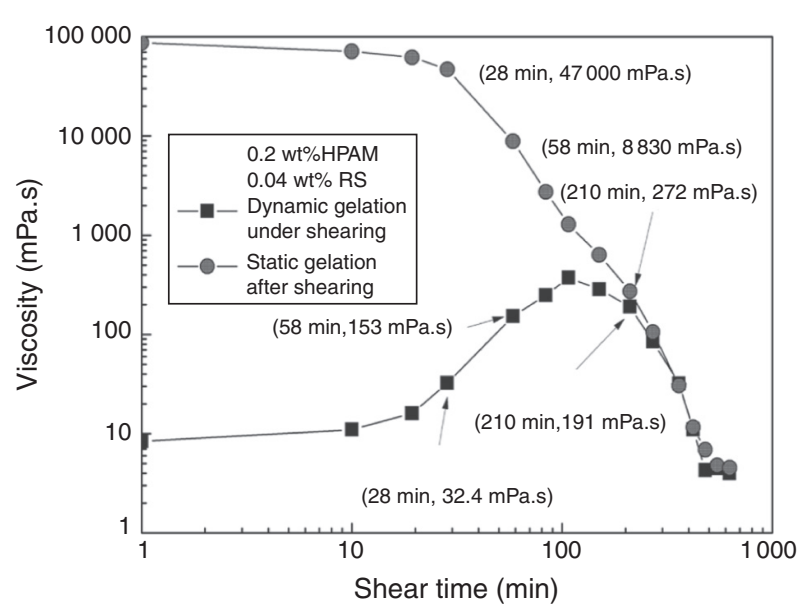

Figure 5

The change of viscosity in the process of static gelation after shearing with the system of $\mathrm{HPAM} / \mathrm{Cr}(\mathrm{III})$ at $75^{\circ} \mathrm{C}$.

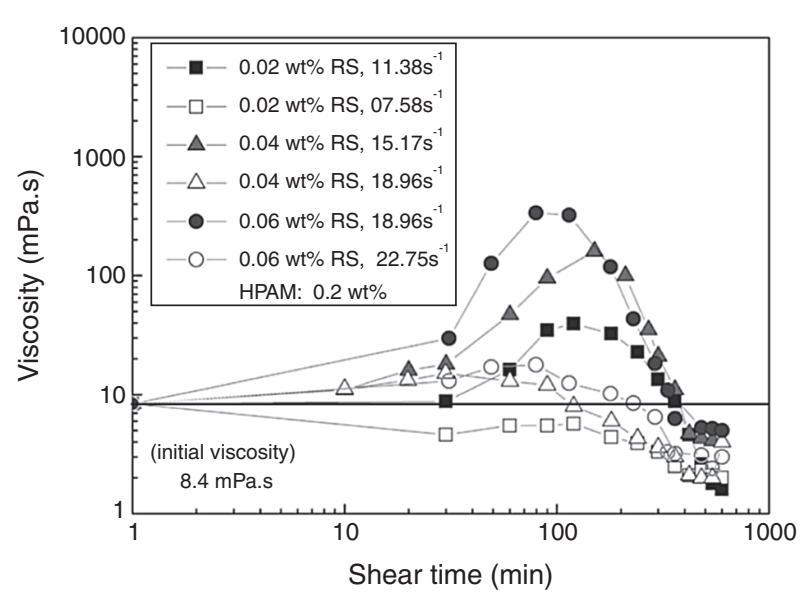

Figure 6

Determination of critical gelation shear rates with different formulas at $75^{\circ} \mathrm{C}$. linearly with shear time and the viscosity of static gelation after shearing for different times decreased linearly with shear time in semilog coordinates. The slopes were 0.022 and -0.024 in semilog coordinates, respectively. At the stage of stability and decrease, the viscosities had almost no difference. Macromolecular aggregates were destroyed by shear at the stage of induction, while the three-dimensional network structure was damaged by shear at the stage of sudden increase.

\subsubsection{Critical Gelation Shear Rate}

With increasing shear rate, gel strength decreased. When the shear rate reached a certain value, the HPAM system and RS could not form gel. There was a critical value of the shear rate, named the critical gelation shear rate, beyond which the system of HPAM/Cr(III) could not form gel. The critical gelation shear rates of different formulas were measured, and the data are shown in Figure 6 . The critical gelation shear rates of different formulas were $11.38 \mathrm{~s}^{-1} \quad(0.2 \quad \mathrm{wt} \%$ HPAM and $0.02 \mathrm{wt} \% \mathrm{RS}), 15.17 \mathrm{~s}^{-1}(0.2 \mathrm{wt} \%$ HPAM and $0.04 \mathrm{wt} \% \mathrm{RS})$ and $18.96 \mathrm{~s}^{-1}(0.2 \mathrm{wt} \%$ HPAM and $0.06 \mathrm{wt} \% \mathrm{RS})$, respectively. This indicated that the critical gelation shear rate increased with increasing crosslinker concentration. Therefore, the higher the gel strength, the higher the critical gelation shear rate.

\subsection{Dynamic Gelation in Porous Media}

When the gelant was transported in porous media at $75^{\circ} \mathrm{C}$, there were two processes. One was the process of reaction between polymer molecules and crosslinkers, which resulted in the formation of gel and buildup of injection pressure. The other one was breakage of the three-dimensional network structure by the following injected gelant and porous media, which led to a pressure drop. So, the gelation time was longer than that in static porous media. When the gelant began to form gel, the injection pressure rose. The change in pressure with time is shown in Figure 7. With increase in time, the injected volume increased and input pressure rose. The process of input pressure was divided into the induction and sudden increase stages. The IGT could be determined by the input pressure, as shown in Figure 7. However, the FGT was difficult to determine. Under low concentrations of polymer and crosslinker, the pressure $\mathrm{P}_{2}$ increased by a certain degree, which represented the gelant migration in porous media. In the process of dynamic gelation in porous media, there were mainly two effect factors: the crosslinking reaction, making input pressure rise, and shear degradation, reducing input pressure. When the concentrations of polymer and crosslinker increased, the IGT decrease was shortened, as shown in Figure 8. Compared with static gelation in porous media and in ampoule bottles, the IGT of dynamic gelation in porous media was much longer, which was about four times the IGT of static gelation in porous media, and eight to ten times the IGT of static gelation in ampoule bottles.

\section{CONCLUSIONS}

Based on the experimental analysis of the HPAM system and Redox System (RS: sodium bichromate and sodium 

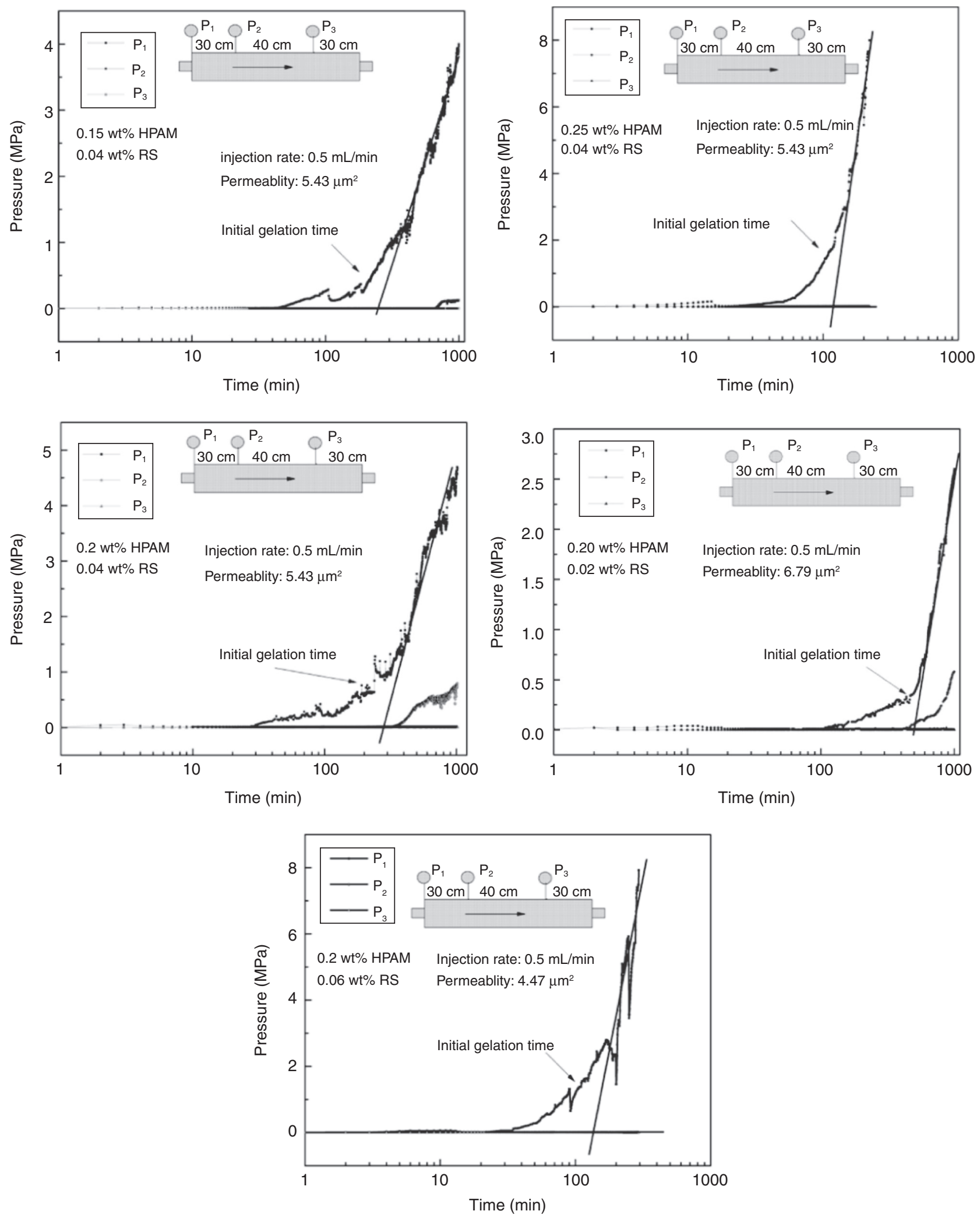

Figure 7

The change of pressure with time in the process of gelant system of $\mathrm{HPAM} / \mathrm{Cr}(\mathrm{III})$ migration in porous media at $75^{\circ} \mathrm{C}$. 

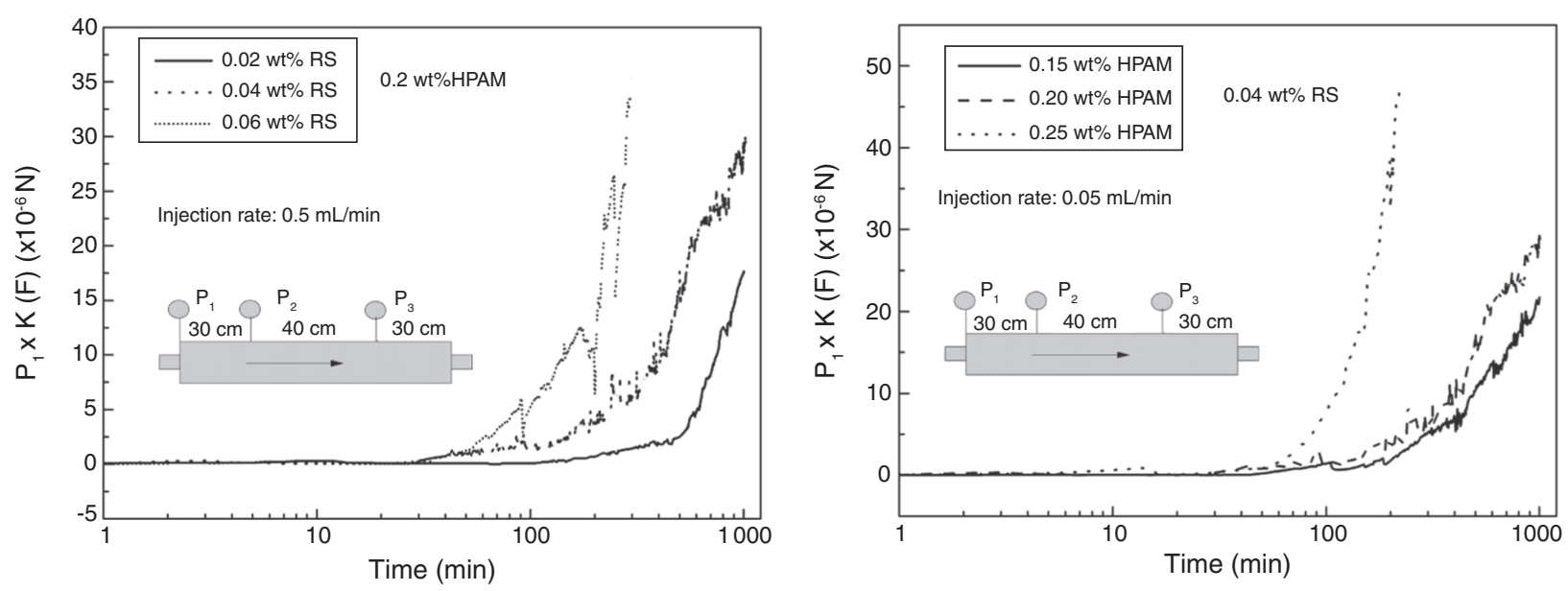

Figure 8

The effect of polymer and crosslinker on dynamic gelation in porous media at $75^{\circ} \mathrm{C}$.

sulfite) at $75^{\circ} \mathrm{C}$, the most important conclusions are summarized as follows:

- the time of static gelation in porous media was much longer than that in ampoule bottles. IGT in porous media were about three times those in ampoule bottles, while FGT in porous media were six times those in ampoule bottles;

- there was a critical gelation shear rate in the process of gelation under shear, beyond which the system could not form gel, and it was enlarged from $11.38 \mathrm{~s}^{-1}$ to $18.96 \mathrm{~s}^{-1}$ with increasing $\mathrm{RS}$ concentration from $0.02 \mathrm{wt} \%$ to $0.06 \mathrm{wt} \%$;

- shear had almost no influence on gel strength during the induction stage, but in the stage of sudden increase, shear could sharply degrade gel strength. The viscosity of a system with $0.2 \mathrm{wt} \%$ HPAM and $0.04 \mathrm{wt} \% \mathrm{RS}$ standing for $40 \mathrm{~min}$ after shearing decreased linearly with time in semilog coordinates and the slope was -0.024 in semilog coordinates;

- the gelation time of dynamic gelation in porous media was much longer than that of static gelation in porous media and ampoule bottles. IGT of dynamic gelation in porous media were about four times the IGT of static gelation in porous media and eight to ten times the IGT of static gelation in ampoule bottles.

\section{ACKNOWLEDGMENTS}

This work was sponsored by the National S\&T Major Project (Grant No.: 2011ZX05024-004) on chemical flooding in Bohai heavy oil reservoir.

\section{REFERENCES}

1 Sydansk R. (1988) A New Conformance-ImprovementTreatment Chromium(III) Gel Technology, SPE/DOE Enhanced Oil Recovery Symposium, Tulsa, Oklahoma, 17-20 April, SPE/DOE paper 17329.

2 Reddy B.R., Eoff L., Dalrymple E.D., Black K., Brown D., Rietjens M. (2003) A Natural Polymer-Based Cross-Linker System for Conformance Gel Systems, SPE J. 8, 2, 99-106.

3 Mokhtari M., Ozbayoglu E.M. (2010) Laboratory Investigation on Gelation Behavior of Xanthan Crosslinked with Borate Intended to Combat Lost Circulation, SPE Production and Operations Conference and Exhibition, Tunis, 8-10 June, SPE paper 136094-MS.

4 Gao S., Guo J., Wu L., Wang S. (2008) Gelation of konjac glucomannan crosslinked by organic borate, Carbohydr. Polym. 73, 3, 498-505.

5 Chambon F., Winter H. (1985) Stopping of crosslinking reaction in a PDMS polymer at the gel point, Polym. Bull. 13, 6, 499-503.

6 Basta M., Picciarelli V., Stella R. (1991) Electrical conductivity in the kinetic gelation process, Eur. J. Phys. 12, 210-213.

7 Boey F., Qiang W. (2000) Determining the gel point of an epoxy-hexaanhydro-4-methylphthalic anhydride (MHHPA) system, J. Appl. Polym. Sci. 76, 8, 1248-1256.

8 Jousset F., Green D.W., Willhite G.P., McCool C.S. (1990) Effect of High Shear Rate on In-Situ Gelation of a Xanthan/ Cr(III) System, SPE/DOE Enhanced Oil Recovery Symposium, Tulsa, Oklahoma, 22-25 April, SPE paper 20213-MS.

9 Tseu J.S., Liang J.T., Hill A.D. (1992) Re-formation of Xanthan/Chromium gels after shear degradation, SPE Reserv Eng. 7, 21-28, SPE paper 18506-PA.

10 Bartosek M., Mennella A., Lockhart T.P., Causin E., Rossi E., Passucci C. (1994) Polymer gels for conformance treatments: propagation of $\mathrm{Cr}$ (III) crosslinking complexes in porous media, SPE/DOE Ninth Symposium on improved oil Recovery, Tulsa, Oklahoma, USA, 17-20 April, SPE paper 27828-MS. 
11 Broseta D., Marquer O., Zaitoun A., Baylocq P., Fery J.-J. (2000) Shear Effects on Polyacrylamide/Chromium (III) Acetate Gelation, SPE Reserv. Eval. Eng. 3, 3, 204-208.

12 McCool S., Li X., Willhite G.P. (2007) Effect of Shear on Flow Properties During Placement and on Syneresis After Placement of a Polyacrylamide Chromium Acetate Gelant, SPE International Symposium on Oilfield Chemistry, Houston, Texas, USA, 28 Feb.-2 March, SPE paper 106059-MS.

13 Chauveteau G., Tabary R., Renard M., Omari A. (1999) Controlling In-Situ Gelation of Polyacrylamides by Zirconium for Water Shutoff, SPE International Symposium on Oilfield Chemistry, Houston, Texas, 16-19 Feb., SPE paper 50752-MS.

14 Bhaskar R.K., Stinson J.A., Willhite G.P., Thiele J.L. (1988) The Effects of Shear History on the Gelation of Polyacrylamide/Chromium VI Thiourea Solutions, SPE Reserv. Eng. 3, 4, 1251-1256.

15 Kolnes J., Stavland A., Thorsen S. (1991) The Effect of Temperature on the Gelation Time of Xanthan/Cr (III) Systems, SPE International Symposium on Oilfield Chemistry, Anaheim, California, 20-22 Feb., SPE paper 21001-MS.
16 McCool C.S., Li X., Willhite G.P. (2009) Flow of a Polyacrylamide/Chromium Acetate System in a Long Conduit, SPE J. 14, 1, 54-66, SPE-106059-PA.

17 Seright R.S. (1997) Use of Preformed Gels for Conformance control in Fractured system, Old Prod. Facil. 12, $1,59-65$.

18 Dolan D.M., Thiele J.L., Willhite G.P. (1998) Effects of pH and Shear on the Gelation of a Xanthan-Cr (III) System, Old Prod. Facil. 13, 2, 97-103.

19 Metzner A., Otto R. (1957) Agitation of non-Newtonian fluids, AIChE J. 3, 1, 3-10.
Manuscript accepted in November 2012 Published online in September 2013

Cite this article as: Y. Haiyang, W. Yefei, Z. Jian, L. Peng and S. Shenglong (2013). Dynamic Gelation of HPAM/Cr(III) under Shear in an Agitator and Porous Media, Oil Gas Sci. Technol 70, 6, 941-949. 